\title{
Photoperiodic induction and termination of summer diapause in adult Epilachna admirabilis (Coleoptera: Coccinellidae) from a warm temperate region
}

\author{
CHobei IMAI \\ Osaka City Institute of Public Health and Environmental Sciences, Tojo-cho, Tennoji, Osaka 543-0026, Japan; \\ e-mail: chobei.imai@iphes.city.osaka.jp
}

Key words. Adult summer diapause, Coccinellidae, diapause development, Epilachna admirabilis, intermediate photoperiodism, latitudinal difference, recurrent photoperiodic response, reproductive diapause, reversible response

\begin{abstract}
In warm temperate and subtropical regions an adult summer diapause regulates the timing of oviposition. Epilachna admirabilis is a univoltine phytophagous lady beetle ranging from south to north Japan, Taiwan, China and Myanmar. In Japan the species hibernates in the full-grown larval stage. In cool temperate Sapporo $\left(43^{\circ} 04^{\prime} \mathrm{N}\right)$ the adults never enter summer diapause but pass a second winter in diapause. This study revealed that in Kyoto $\left(35^{\circ} 01^{\prime} \mathrm{N}\right)$, the adults had a summer diapause induced by an intermediate photoperiodic response; they had a critical photoperiod of approximately $14.5 \mathrm{~h}$ light per day. All females entered reproductive diapause under a long photoperiod of $16 \mathrm{~L}$ (light) : 8D (dark) and $6.7 \%$ of them did so under shorter photoperiods of 13L : 11D and 12L : 12D. However, diapause incidence was 40\% at 8L:16D, suggesting the existence of a second critical photoperiod at a photophase slightly less than $8 \mathrm{~h}$. At photophases of $12-15 \mathrm{~h}$, non-diapausing females laid eggs on average between 27.1 to 39.0 days after emergence. Photoperiod reversibly regulated the induction, maintenance and termination of the adult diapause. Temperatures of $20-30^{\circ} \mathrm{C}$ did not affect the incidence and termination of diapause at $16 \mathrm{~L}: 8 \mathrm{D}$. Adult winter diapause at the higher latitude Sapporo might have originated from adult summer diapause at middle latitude regions such as Kyoto. Selection at increasing latitudes would have forced northerly populations of the species to lose the adult summer diapause in the range of natural daylengths. Subsequent selection pressure should have favored adults that avoided futile oviposition in late summer or autumn, survived cold winters in diapause and commenced an additional oviposition in the second summer. Thus, a latitudinal difference in photoperiodic responses might have developed.
\end{abstract}

\section{INTRODUCTION}

Diapause halts or delays development of insects at specific developmental stages, and enables synchronisation of life cycles to season (Danilevskii, 1961; Tauber \& Tauber, 1976; Danks, 1987). Diapause in the adult stage regulates the timing of oviposition of many species (Danilevskii, 1961; Masaki, 1980; Danks, 1987).

Adult winter diapause has been reported in many species of long-day insect (Danilevskii, 1961; Tauber \& Tauber, 1976; Danks, 1987) including most Coccinellidae species (Hodek, 1996). In the lady beetles of genus Epilachna, ovarian diapause is induced by short day-length in E. vigintioctomaculata (Maki et al., 1964), E. vigintioctopunctata (Kono, 1986) and E. varivestis (Taylor \& Schrader, 1984) as well as the cool temperate Sapporo population of E. admirabilis (Hoshikawa, 2000).

The ten-spotted lady beetle E. admirabilis Crotch is a univoltine species feeding on wild cucurbits such as Gynostemma pentaphyllum, Trichosanthes cucumeroides, T. kirilowii and Schizopepon bryoniaefolius. The food plants are perennial herbaceous lianas; their biomass is very small in spring becoming maximal in late summer. In Japan this lady beetle ranges from Hokkaido (northernmost) to Kyushu and is also present in Taiwan, China and Myanmar (Kurosawa et al., 1985). In contrast to most Coccinellidae species, E. admirabilis hibernates as a fullgrown larva in warm (Kawano, 1934; Takeuchi \&
Tamura, 1994) and cool (Katakura, 1976; Hoshikawa, 1980) temperate zones. In addition, some individuals enter a second hibernation in the adult stage (Katakura, 1976; Hoshikawa, 1981; Takeuchi \& Tamura, 1994).

In warm temperate Tokyo $\left(35^{\circ} 30^{\prime} \mathrm{N}\right)$, the posthibernating larvae pupate in April. The adults emerge between late-April and early-May and begin oviposition in mid-July (Kawano, 1934; Takeuchi \& Tamura, 1994). Similar findings were also obtained in Kyoto City $\left(35^{\circ} 01^{\prime} \mathrm{N}\right.$; Imai, unpubl.). The observations suggest that the adults enter a summer diapause (Masaki, 1980). If this is true, the species must have two different types of adult diapause; a winter diapause in cool temperate regions such as Sapporo and a summer diapause in warm temperate regions such as Tokyo and Kyoto.

This study was conducted in Kyoto City to clarify the life history traits of E. admirabilis in warm temperate Japan.

\section{MATERIAL AND METHODS}

Adults were collected within $24 \mathrm{~h}$ of emergence from tree trunks close to ground level in the Botanical Garden of Kyoto University, urban Kyoto, on 6-11 May 1972.

One female and two males were placed in a plastic cup and fed on fresh leaves of G. pentaphyllum. Each leaf consisted of one rachis and five leaflets. The adults feed on the epiderm of one side of the leaflets. Opposite to each rachis grows a tendril on which the females lay eggs. Rearing conditions were $25^{\circ} \mathrm{C}$, $70-80 \%$ RH. Fifteen replicates were prepared for each of the 
TABLE 1. Oviposition under different photoperiods at $25^{\circ} \mathrm{C}$.

\begin{tabular}{|c|c|c|c|c|c|c|c|}
\hline \multirow{2}{*}{ Photoperiod } & \multirow{2}{*}{$\mathrm{N}$} & \multicolumn{2}{|c|}{ Ovipositing females } & \multicolumn{2}{|c|}{ Pre-oviposition period (d) } & \multicolumn{2}{|c|}{ Number of eggs ${ }^{2}$} \\
\hline & & Percent & $\mathrm{N}$ & Average & $95 \%$ C. I. ${ }^{1}$ & Average & $95 \%$ C. I. \\
\hline $8 \mathrm{~L}: 16 \mathrm{D}$ & 15 & 60.0 & 9 & 28.9 & $25.2-32.6$ & 15.8 & $7.6-24.0$ \\
\hline $12 \mathrm{~L}: 12 \mathrm{D}$ & 15 & 93.3 & 14 & 33.7 & $29.1-38.3$ & 28.4 & $16.7-40.1$ \\
\hline $13 \mathrm{~L}: 11 \mathrm{D}$ & 15 & 93.3 & 14 & 27.1 & $25.0-29.2$ & 38.5 & $26.6-50.4$ \\
\hline $14 \mathrm{~L}: 10 \mathrm{D}$ & 15 & 80.0 & 12 & 34.8 & $28.1-41.5$ & 15.4 & $7.4-23.4$ \\
\hline $15 \mathrm{~L}: 9 \mathrm{D}$ & 15 & 13.3 & 2 & 39.0 & - & 10.0 & - \\
\hline
\end{tabular}

${ }^{1}$ confidence interval. ${ }^{2}$ eggs laid per reproductive female for the initial 10 days after the beginning of oviposition.

following photoperiods: 8L (light) : 16D (dark), 12L : 12D, 13L : 11D, 14L : 10D, 15L : 9D and 16L : 8D. Once a day, food consumption and number of eggs were recorded and fresh leaves supplied.

Under a long day-length of $16 \mathrm{~L}: 8 \mathrm{D}$, fifteen replicates were held at $20^{\circ} \mathrm{C}$ or $30^{\circ} \mathrm{C}$ for 55 days after emergence. The procedure for manipulating the photoperiods is given in Table 2 .

In addition, 38 pairs of newly emerged adults were exposed to room temperature (approximately $16-27^{\circ} \mathrm{C}$ depending on seasons) under natural day-length by the end of July. On 1 August, seven pairs were transferred to $30^{\circ} \mathrm{C}, 16 \mathrm{~L}: 8 \mathrm{D}$, and 31 pairs to $25^{\circ} \mathrm{C}, 16 \mathrm{~L}: 8 \mathrm{D}$. Twelve of the 31 pairs were again transferred to room temperature and natural day-length on 21 August. This experiment finished on 26 September.

Six females and three males, which had been marked with lacquer paints and released in the summer of 1971, were recaptured in 28 May-24 June 1972. These were maintained on fresh leaves and tendrils at room temperature under natural day-length until they died in mid-July (the last death occurred on 17 July).

\section{RESULTS}

\section{Photoperiodic response curve}

The percentages of females that laid eggs within 70 days after emergence ranged between $0 \%$ at $16 \mathrm{~L}: 8 \mathrm{D}$ and $93.3 \%$ at $12 \mathrm{~L}: 12 \mathrm{D}$ and $13 \mathrm{~L}: 11 \mathrm{D}$ (Table 1). Females that did not lay any eggs within 70 days were considered to have entered a reproductive diapause. Thus diapause incidence (\%) was estimated as 100 minus percent oviposition. Adult females showed a short-day response with a critical photoperiod of approximately $14.5 \mathrm{~h}$ light per day in the range of naturally relevant photoperiods in Kyoto

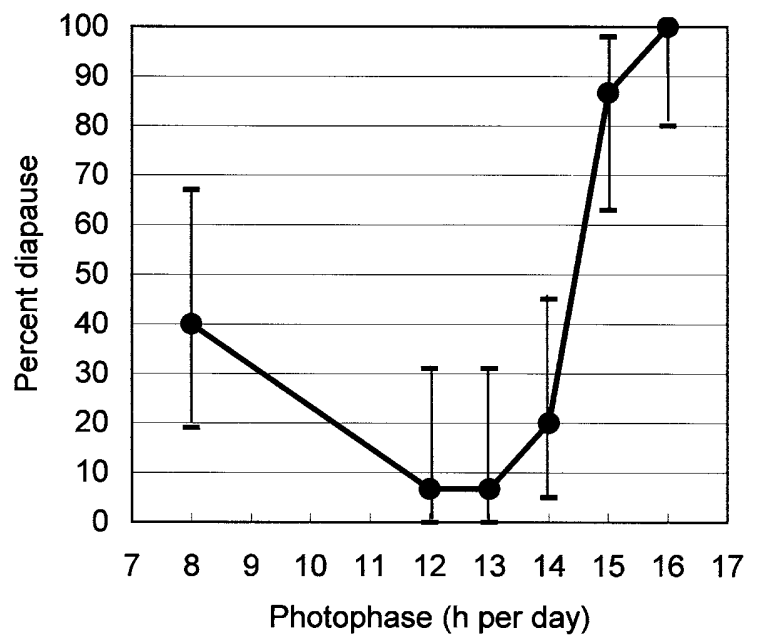

Fig. 1. Photoperiodic response curve of adult Epilachna admirabilis from Kyoto at $25^{\circ} \mathrm{C}$. Vertical lines are $95 \%$ confidence intervals. (approximately 11-15.5 h light), but another threshold was suggested at a photophase slightly less than $8 \mathrm{~h}$ (Fig. $1)$.

\section{Adult food consumption}

On average an adult consumed approximately one leaf of $G$. pentaphyllum per day during the initial ten days following emergence. Then, the daily amount of food taken by reproductive adults decreased by approximately a half and diapausing adults ate none or only small parts of leaves.

\section{Pre-oviposition period and egg-laying}

The pre-oviposition period of non-diapausing females was shortest under 13L : 11D. A long pre-oviposition period of 66 days was observed in one female under 14L : 11D. The average number of eggs per female during the first 10 days after the beginning of oviposition ranged between 10.0 and 38.5 , under 15L : 9D and 13L : 11D, respectively, with large variances under most photoperiods (Table 1).

\section{Effect of temperature under a long photoperiod}

Females reared at $20^{\circ} \mathrm{C}$ or $30^{\circ} \mathrm{C}$ under a long photoperiod of $16 \mathrm{~L}: 8 \mathrm{D}$ did not lay any eggs, similar to those reared at $25^{\circ} \mathrm{C}$. The survival of diapausing adults decreased with time at $30^{\circ} \mathrm{C}$ but mortality did not increase during a period of 55 days after emergence at $25^{\circ} \mathrm{C}$ (Fig. 2). Moreover, survival did not decrease at $20^{\circ} \mathrm{C}$.

Diapausing females at $30^{\circ} \mathrm{C}$ or $25^{\circ} \mathrm{C}$ under $16 \mathrm{~L}: 8 \mathrm{D}$ did not commence oviposition even after they were transferred to a lower temperature of $25^{\circ} \mathrm{C}$ or $20^{\circ} \mathrm{C}$ respectively. A similar result was obtained when the rearing
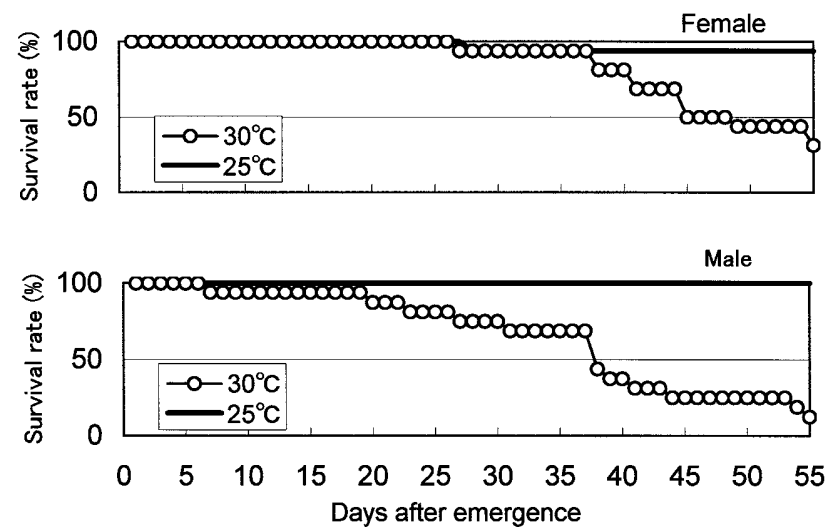

Fig. 2. Survival curves of diapausing adults at $25^{\circ} \mathrm{C}$ and $30^{\circ} \mathrm{C}$ under a photoperiod of $16 \mathrm{~L}: 8 \mathrm{D}$. Initial numbers were 15 females and 30 males. 
TABLE 2. Effect of changing photoperiods on adult reproductive diapause at $25^{\circ} \mathrm{C}$.

\begin{tabular}{|c|c|c|c|c|c|c|c|c|c|c|}
\hline \multirow{2}{*}{ Exp. } & \multirow{2}{*}{$\mathrm{N}$} & \multicolumn{3}{|c|}{ First phase } & \multicolumn{3}{|c|}{ Second phase } & \multicolumn{3}{|c|}{ Third phase } \\
\hline & & Duration & Photoperiod & No. of eggs & Duration & Photoperiod & No. of eggs & Duration & Photoperiod & No. of eggs \\
\hline A1 & 5 & $1-40$ & $8 \mathrm{~L}: 16 \mathrm{D}$ & $14.4 \pm 6.7$ & $41-70$ & $8 \mathrm{~L}: 16 \mathrm{D}$ & $5.2 \pm 6.0$ & - & - & - \\
\hline $\mathrm{A} 2$ & 2 & & & 30.0 & & $16 \mathrm{~L}: 8 \mathrm{D}$ & 2.5 & - & - & - \\
\hline B1 & 5 & & & $23.2 \pm 5.5$ & & $12 \mathrm{~L}: 12 \mathrm{D}$ & $9.2 \pm 13.2$ & & $12 \mathrm{~L}: 12 \mathrm{D}$ & $1.6 \pm 4.4$ \\
\hline B2 & 2 & $1-40$ & $12 \mathrm{~L}: 12 \mathrm{D}$ & 50.0 & $41-55$ & $16 \mathrm{~L}: 8 \mathrm{D}$ & 4.5 & $56-70$ & $16 \mathrm{~L}: 8 \mathrm{D}$ & 0.0 \\
\hline B3 & 1 & & & 49 & & $16 \mathrm{~L}: 8 \mathrm{D}$ & 0 & & 13L : 11D & 3 \\
\hline $\mathrm{C} 1$ & 5 & & & $45.8 \pm 24.7$ & & $13 \mathrm{~L}: 11 \mathrm{D}$ & $32.4 \pm 8.2$ & & $13 \mathrm{~L}: 11 \mathrm{D}$ & $2.2 \pm 2.0$ \\
\hline $\mathrm{C} 2$ & 2 & $1-35$ & 13L : 11D & 61.0 & $36-55$ & $16 \mathrm{~L}: 8 \mathrm{D}$ & 4.5 & $56-70$ & $16 \mathrm{~L}: 8 \mathrm{D}$ & 0.0 \\
\hline $\mathrm{C} 3$ & 3 & & & $33.3 \pm 59.9$ & & $16 \mathrm{~L}: 8 \mathrm{D}$ & 0.0 & & 13L : 11D & $11.3 \pm 22.5$ \\
\hline D1 & 4 & & & $24.3 \pm 28.4$ & & 14L : 10D & $5.8 \pm 12.1$ & & 14L : 10D & 0.0 \\
\hline D2 & 1 & $1-45$ & $14 \mathrm{~L}: 10 \mathrm{D}$ & 45 & $46-60$ & $16 \mathrm{~L}: 8 \mathrm{D}$ & 0 & $61-70$ & $16 \mathrm{~L}: 8 \mathrm{D}$ & 0 \\
\hline D3 & 2 & & & 22.0 & & $16 \mathrm{~L}: 8 \mathrm{D}$ & 0.0 & & 13L : 11D & 20.0 \\
\hline E1 & 7 & $1-50$ & $16 \mathrm{~L}: 8 \mathrm{D}$ & 0.0 & $51-70$ & $16 \mathrm{~L}: 8 \mathrm{D}$ & 0.0 & - & - & - \\
\hline E2 & 6 & & & 0.0 & & 13L : 11D & $9.3 \pm 7.4$ & - & - & - \\
\hline
\end{tabular}

temperature was decreased from $30^{\circ} \mathrm{C}$ via $25^{\circ} \mathrm{C}$ to $20^{\circ} \mathrm{C}$ under $16 \mathrm{~L}: 8 \mathrm{D}$.

\section{Effect of transfer between longer and shorter photoperiods}

Non-diapausing females reproducing under photophases of 8-14 h per day ceased oviposition after they were transferred to a long photophase of $16 \mathrm{~h}$. These females resumed oviposition after they were exposed to a shorter photophase of $13 \mathrm{~h}$ (Table 2). Non-diapausing females entered diapause within seven days after transfer to a diapause-inducing photoperiod (16L : 8D) and, conversely, diapausing females resumed oviposition within five days after they were exposed to a diapauseterminating photoperiod (13L : 11D).

Similar results were obtained under semi-natural conditions (Fig. 3). Females that had been exposed to room temperature under natural day-length began oviposition on 26 July, when natural day-length including $1 \mathrm{~h}$ civil twilight (hereafter, simply called day-length) was approximately $15 \mathrm{~h}$. However, they ceased oviposition within six days after transfer to $16 \mathrm{~L}: 8 \mathrm{D}$ at $25^{\circ} \mathrm{C}$ or $30^{\circ} \mathrm{C}$ on 1 August and no egg was laid until late September (the end of the experiment) under the same long-day condition. Such diapausing females recommenced oviposition 12-19 days after they were again transferred to room temperature and natural day-length on 21 August, when day-length was approximately $14 \mathrm{~h}$.

\section{Oviposition of post-hibernating females}

Recapture rates of adults after hibernation were $13.1 \%$ (6 of 46) in females and 7.5\% (3 of 40) in males. These post-hibernating adults did not lay any eggs under natural day-length of 15.2-15.5 h until they died in mid-July.

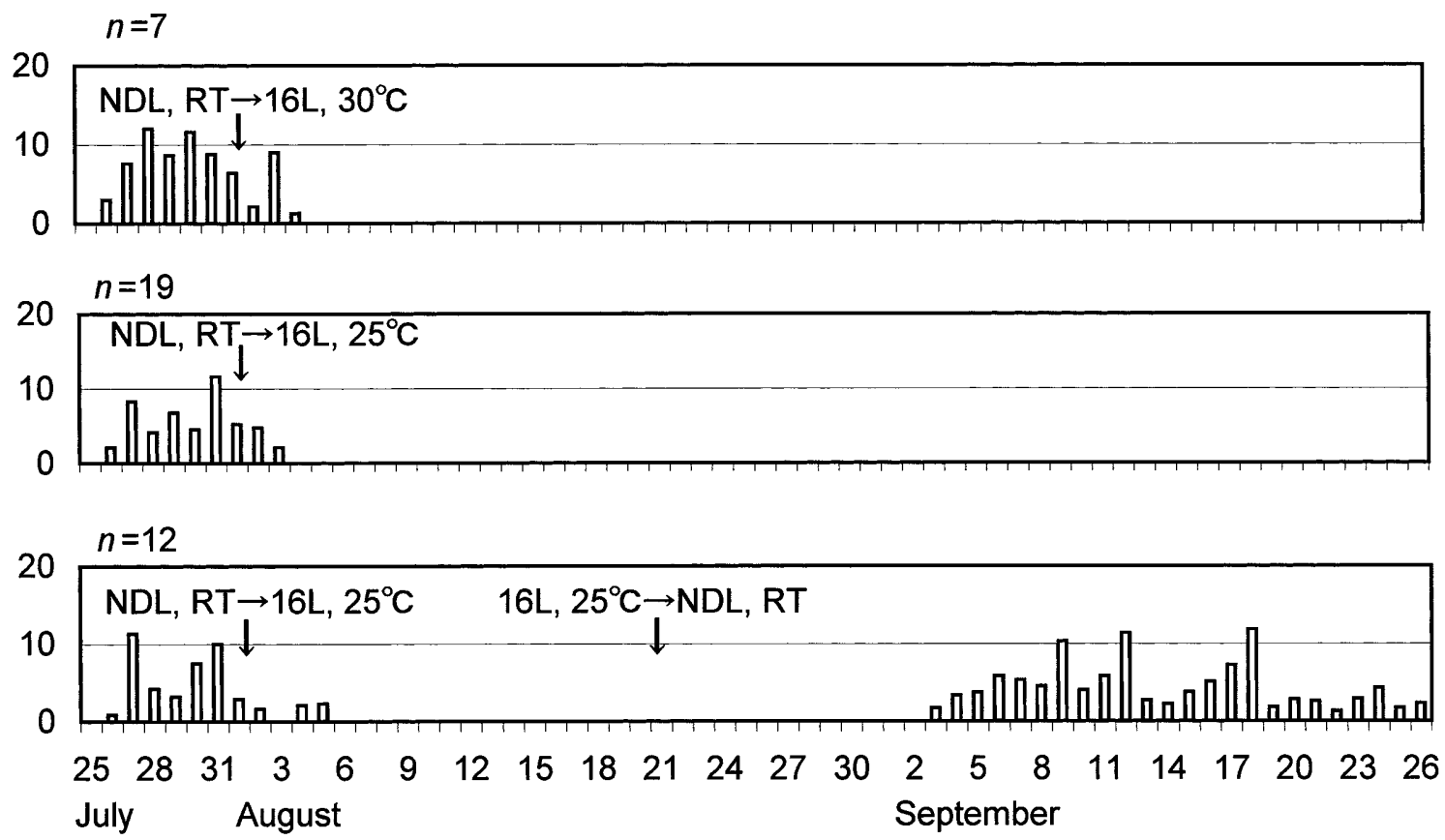

Fig. 3. Oviposition by females under conditions alternating between natural day-length and 16L : 8D. Combined downward and sideway arrows show dates of changes. NDL, RT and 16L mean natural day-length, room temperature and 16L : 8D photoperiod, respectively. For further details, see the legend of Table 1. 


\section{DISCUSSION}

\section{Adult summer diapause}

The Kyoto population of E. admirabilis was confirmed to have a summer diapause (Masaki, 1980) in the adult stage. Females enter reproductive diapause as a response to day-length longer than a critical photoperiod of approximately $14.5 \mathrm{~h}$. Diapausing adults took none, or only a small amount of foods. Similar results were obtained in the field (Imai, unpubl.). Therefore, in the Kyoto population of E. admirabilis, reproductive diapause is associated with aestival dormancy.

Similar adult summer diapause is reported in short-day insects such as the carabid beetles Nebria brevicollis and Patrobus atrorufus (Thiele, 1969), the vegetable weevil Listroderes costirostris obliquus (Matsumoto, 1959), the alfalfa weevil Hypera postica (Huggans \& Blickenstaff, 1964), the Egyptian alfalfa weevil H. brunneipennis (Chuka Madubunyi, 1978), the burying beetle Nicrophorus quadripunctatus (Nisimura et al., 2002), the satyrine butterfly Minois dryas (Kida et al., 1997), the oriental green stink bug Nezera antennata (Noda, 1984), the cabbage bug Eurydema rugosum (Ikeda-Kikue \& Numata, 2001), and Poecilocoris lewisi bug (Tanaka et al., 2002). Many other examples are described in Masaki (1980) and Danks (1987).

\section{Duration of diapause}

Diapause intensity varies among individuals within the same species (Tauber \& Tauber, 1976; Danks, 1987). The pre-oviposition period of one female under 14L : 10D was as long as 66 days. This female, although defined as non-diapausing in this paper, may have entered a short diapause and terminated it without any environmental cue. This experiment finished 70 days after adult emergence and it is therefore unknown whether a long diapause of over 70 days can be terminated without any environmental changes. Nonetheless there is a report that adult summer diapause in the vegetable weevil $L$. cost $i$ rostris obliquus was maintained for more than 199 days at 16L : 8D (Matsumoto, 1959).

\section{Effect of temperature on diapause}

Photoperiodic response varies depending on temperature in many species (e.g., McMullen, 1967; Tauber \& Tauber, 1976; Danks, 1987; Gomi, 1997; Nisimura et al., 2002). In E. admirabilis, however, different level of and stepwise decrease in temperature of $30^{\circ} \mathrm{C}, 25^{\circ} \mathrm{C}$ and $20^{\circ} \mathrm{C}$ did not affect the incidence and termination of diapause under a long photoperiod of $16 \mathrm{~L}: 8 \mathrm{D}$. The effect of temperature at the other photoperiods is unknown but the present results suggest that if there is any it is small.

A high temperature of $30^{\circ} \mathrm{C}$ induced great mortality in diapausing adults, whereas lower temperatures of $25^{\circ} \mathrm{C}$ and $20^{\circ} \mathrm{C}$ showed no such effect.

\section{Reversibility of photoperiodic induction, maintenance and termination of diapause}

In E. admirabilis, photoperiod reversibly regulates the induction, maintenance and termination of the adult diapause.
A similar reversible or recurrent photoperiodic control of ovarian development is reported in the bean bug Riptortus clavatus (Numata \& Hidaka, 1982), the squash bug Anasa tristis (Nechols, 1988), the willow leaf beetle Plagiodera versicolora (Ishihara \& Hayashi 2000) and the lady beetle E. vigintioctomaculata (Maki et al., 1964). However, in contrast to the Kyoto population of $E$. admirabilis, the above mentioned four insects are long-day species. Summer diapause is usually induced by long day-length and terminated by short day-length (Masaki, 1980). The current result is a new example of the photoperiodic control of adult summer diapause.

\section{Photoperiodic sensitivity and diapause development in newly emerged adults}

Many species that enter adult diapause are sensitive to photoperiodic cues in the few days to a week after emergence (Danks, 1987). However, the bug Pyrrhocoris apterus is sensitive throughout the whole life (Hodek, 1968). Similarly, in E. admirabilis, the photoperiodic sensitivity of newly emerged adults lasts at least from spring to autumn.

Diapause development is a process that may end either with, or without, specific cues (Danks, 1987). In E. admirabilis, experimental manipulation of photoperiods suggests that seven long days (16L : 8D) are required to induce adult diapause and that five short days (13L : 11D) are required to terminate it. Moreover the experiment in semi-natural conditions suggests that 12-19 days with day-length decreasing daily from $14 \mathrm{~h}$ are required to terminate the diapause. Thus, diapause development in $E$. admirabilis is accelerated remarkably by stationary or shortening day-length below the critical level. However, we do not know whether diapause development proceeds under diapause-inducing long-day conditions when the adults are exposed to them for longer than 70 days.

\section{Adult hibernation and post-hibernation sensitivity to photoperiod}

Mark-release-recapture studies clarified that a number of adults enter the second hibernation (diapause or quiescence) in Kyoto as at Sapporo (Katakura, 1976; Hoshikawa, 1981) and Tokyo (Takeuchi \& Tamura, 1994). In the Sapporo population, adults enter a hibernating diapause as a response to short day-length of $<14.5 \mathrm{~h}$ (Hoshikawa, 2000). In Kyoto City, day-length is approximately $11 \mathrm{~h}$ in late November. Fig. 1 suggests that the diapause incidence of the Kyoto population is far less than $40 \%$ under such day-length. Therefore, only a small number of adults are considered to enter winter diapause as their second hibernation in Kyoto.

Post-hibernating females did not lay any eggs before they died in mid-July when day-length was still long enough to induce or maintain reproductive diapause. A similar death of post-hibernating adults is also known in Tokyo (Takeuchi \& Tamura, 1994). This may suggest that they either never lost sensitivity to photoperiod and entered reproductive diapause as a response to long daylength, or that they lost reproductive ability after hibernation. 
In E. vigintioctomaculata, both post-hibernating females and newly emerged individuals that had experienced $5^{\circ} \mathrm{C}$ for 40 days lost their sensitivity to photoperiod and developed ovaries irrespective of day-length (Maki \& Kurihara, 1965). Conversely, in the Sapporo population of E. admirabilis, post-hibernating females did not lose the photoperiod sensitivity and these insects began and stopped oviposition as a response to long and short daylength, respectively (Hoshikawa, 2000). Similarly, in the Kyoto and Tokyo populations of the same species, post hibernating females might maintain a sensitivity to photoperiod although the females that can lay eggs in the second year would be few because of the long time interval before the oviposition season.

Hodek (1971) reported the restoration of the photoperiodic response after diapause in adult Aelia acuminata bugs and he predicted that this type of post-diapause regulatory mechanism of reproduction would be observed in many other insect species (Hodek, 1999). Epilachna admirabilis is one of such species. For a review on recurrent photoperiodic response see Hodek \& Hodková (1992).

\section{Intermediate photoperiodic response}

Epilachna admirabilis has an intermediate form (Danilevskii, 1961) of photoperiodism. The photoperiodic response curve is almost a mirror image of that observed in the aedine mosquito Aedes atropalpus (Beach \& Craig Jr., 1977) and the bean bug $R$. clavatus (Numata \& Hidaka, 1982).

Intermediate responses with two critical photoperiods occur in larvae of the cabbage moth Mamestra brassicae (Masaki, 1956), prepupae of the sawfly Athalia japonica (Nagasaka, 1992; Uchidoi \& Takeda, 1997) and adults of the aphidophagous lady beetle Coccinella novemnotata (McMullen, 1967). In these multivoltine species, their spring generation enters summer diapause as a response to long day-length, while their autumn generation enters winter diapause as a response to short day-length. In contrast, the Kyoto population of E. admirabilis encounters with and responds to only one, longer critical photoperiod through its whole life in the field.

\section{Intermediate photoperiodism might have caused two different forms of adult diapause}

In the Sapporo $\left(43^{\circ} 04^{\prime} \mathrm{N}\right)$ population of E. admirabilis, new adults emerge in late June to early July and begin oviposition in mid- to late July. They then enter reproductive diapause in mid-August as a response to short daylength $<14.5 \mathrm{~h}$ (Hoshikawa, 2000). This population is of long-day type in contrast to the Kyoto $\left(35^{\circ} 01^{\prime} \mathrm{N}\right)$ population, at least, in the range of naturally relevant photophases.

Similar relations are known in other univoltine species. In the pentatomid bug Carbula humerigera, the Tottori $\left(35^{\circ} 30^{\prime} \mathrm{N}\right)$ population enters adult summer diapause at long day-length (Fukuda \& Chiyonishio, 1981) while the Hirosaki $\left(40^{\circ} 37^{\prime} \mathrm{N}\right)$ population enters adult reproductive diapause at short day-lengths although adult hibernation has not been determined (Kiritani, 1987). This species hibernates in nymphal diapause in both the north (Kiritani, 1987) and south populations (Fukuda \& Chiyonishio, 1981), similar to E. adimirabilis. In adults of the aphidophagous lady beetle Coccinella septempunctata, the subspecies $C$. s. septempunctata in higher latitude central Europe and central Asia has a long-day response while the subspecies C. s. brucki in lower latitude central Japan has a short-day response (Hodek et al., 1984). Even within the same subspecies $C$. s. brucki, the higher latitude Sapporo population demonstrates a long-day response (Okuda \& Hodek, 1994). Hereafter, a speculation is proposed as for latitudinal difference in the photoperiodic responses of E. admirabilis in Japan.

In long-day species, such as two species of moth Acronycta rumicis (Danilevskii, 1961) and Hyphantria cunea (Gomi, 1997), the green lacewing Chrysopa carnea (Tauber \& Tauber, 1972) and a predatory bug Orius sauteri (Ito \& Nakata, 2000), the photoperiodic response (PR) curve and the critical photoperiod shift towards longer photophases as the latitudes of their habitats increase. Similar latitudinal clines of PRs are reported in many other long-day species (Danks, 1987).

Since Epilachna species might have originated in the low latitude localities where they are most diversified (Schaefer, 1983), E. admirabilis must have expanded its distribution from low- to higher latitudes in Japan while maintaining a univoltine life cycle. Both in Sapporo (Katakura, 1976; Hoshikawa, 2000) and Kyoto this lady beetle hibernates in the full-grown larval stage, although some individuals may pass the second winter as adults. In higher latitude areas, where day-length is longer from vernal to autumnal equinox and temperature is always lower, adults of this univoltine insect emerge later and they have to lay eggs earlier to enable their progenies to complete egg-to-larval development before larval hibernation. Thus, the duration of adult summer diapause would become shorter at higher latitudes (Masaki, 1980). To realize this, the insects have to shift their PR curve and critical photoperiod towards longer photophases and shorten the range of diapause-preventing photophases.

In Sapporo, E. admirabilis lost adult summer diapause while it acquired a "winter" (late August to April) diapause induced by short day-length (Hoshikawa, 2000). There is no information on the critical latitude at which summer diapause was lost, but it may have been either at the latitude of Sapporo or a slightly more southern locality.

We assume here that the summer diapause was lost when a northerly dispersing population arrived at Sapporo. As schematically shown in Fig. 4, natural selection for increasing latitudes might have forced this population to avoid adult summer diapause by modifying its PR curve to the form of curve-A. In curve-A PRs, diapauseinducing photophases are longer than the naturally relevant day-length in Sapporo (10-16.5 h), the range of diapause-terminating photophases is narrower than that of the Kyoto population and diapause incidences are slightly higher than those in the Kyoto population at photophases shorter than diapause-terminating ones. The last one of 


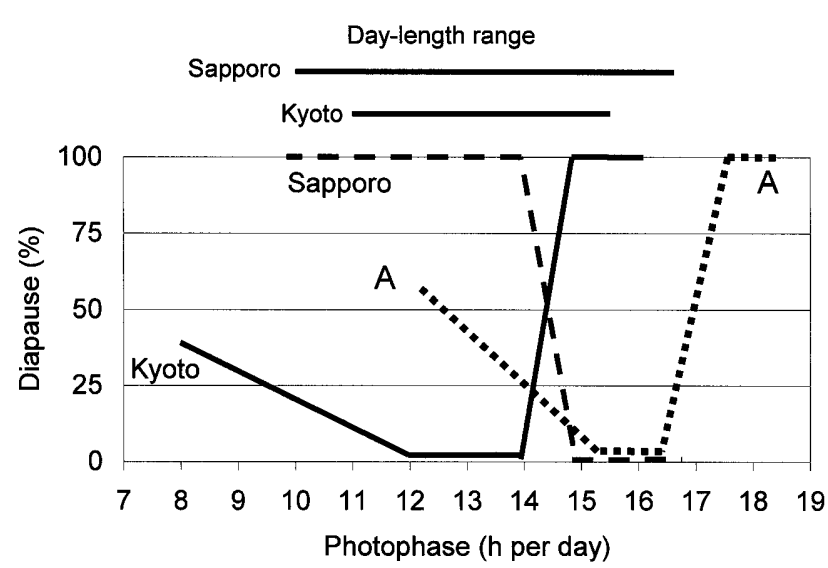

Fig. 4. The suggested evolution of the long-day Sapporo population from the intermediate type Kyoto population of $E$. admirabilis. Photoperiodic response curve of Sapporo population is based on the results by Hoshikawa (2000). Curve A is unconfirmed imaginary photoperiodic response curve at an intermittent step from the Kyoto towards the Sapporo population. Refer to text for further details.

these changes might have developed as an adaptation to colder winters at higher latitudes compared to that of Kyoto.

However, the PRs of curve-A do not enable most adults to enter winter diapause because of low diapause incidence at the naturally relevant photophases of $<15 \mathrm{~h}$. Under such circumstances, individuals that enter adult diapause and survive cold winters in Sapporo (mean temperature is $-4.6^{\circ} \mathrm{C}$ in January; National Astronomical Observatory, 1994) will obtain high fitness if they can commence the second oviposition in the following summer. Natural selection for a second oviposition might have driven adult winter diapause in the population that arrived at Sapporo. Thus, the population with PR curve-A would have been forced to increase diapause incidence to $100 \%$ at photophases $<14 \mathrm{~h}$ and, as a result, developed a long-day PR with a critical photoperiod of approximately $14.5 \mathrm{~h}$, that is, in the range of naturally relevant photophases in Sapporo. Adult diapause at photophases $<14.5$ $\mathrm{h}$ also enables the population to avoid futile oviposition in late August or later, when the remaining summer is insufficient to complete larval development before the onset of winter (Hoshikawa, 2000).

Thus, the long-day Sapporo population must have changed from the intermediate diapause type of the Kyoto population to a northern population with curve-A PRs shown in Fig. 4 or with similar responses.

ACKNOWLEDGEMENTS. I wish to thank S. Utida of Kyoto University and F. Takahashi of Hiroshima University for invaluable advices throughout the course of this study. I am grateful to I. Hodek, for his great encouragement and valuable suggestion in reviewing the manuscript.

\section{REFERENCES}

BEACH R.F. \& CRAIG JR. G.B. 1977: Night length measurements by the circadian clock controlling diapause induction in the mosquito Aedes atropalpus. J. Insect Physiol. 23: 865-870.
Chuka Madubunyi L. 1978: External environmental factors regulating imaginal diapause in Hypera brunneipennis. Ann. Entomol. Soc. Am. 71: 37-39.

DANilevskil A.S. 1961: Photoperiodism and Seasonal Development of Insects. Leningrad Univ. Press, Leningrad, 283 pp.

Danks H.V. 1987: Insect Dormancy: An Ecological Perspective. Biological Survey of Canada, Ottawa, 439 pp.

Fukuda H. \& ChiYonishio T. 1981: Studies on the pentatomid bugs. 3. Some ecological observations and the seasonal prevalence of Carbula humerigera Uhler in the paddy fields of mountainous region in Tottori prefecture. Bull. Tottori Agric. Exp. Stn. 19: 49-58.

Gomi T. 1997: Geographic variation in critical photoperiod for diapause induction and its temperature dependence in Hyphantria cunea Drury (Lepidoptera: Arctiidae). Oecologia 111: $160-165$.

HodeK I. 1968: Diapause in females of Pyrrhocoris apterus L. (Heteroptera). Acta Entomol. Bohemoslov. 65: 422-435.

Hodek I. 1971: Sensitivity to photoperiod in Aelia acuminata (L.) after adult diapause. Oecologia 6: 152-155.

Hodek I. 1996: Dormancy. In: Hodek I. \& Honěk A. (eds): Ecology of Coccinellidae. Kluwer Academic Publishers, Dordrecht, $464 \mathrm{pp}$.

Hodek I. 1999: Environmental regulation and some neglected aspects of insect diapause. Entomol. Sci. 2: 533-537.

Hodek I. \& Hodková M. 1992: Regulation of postdiapause reproduction by recurrent photoperiodic response. In Bennettová B., Gelbič I. \& Soldán T. (eds): Advances in Regulation of Insect Reproduction. Institute of Entomology, Czech Acad. Sci., České Budějovice, pp. 119-124.

Hodek I., OKuda T. \& HodkovÁ M. 1984: Reverse photoperiodic responses in two subspecies of Coccinella septempunctata L. Zool. Jb. Syst. 111: 439-448.

HoshiKawa K. 1980: Notes on the larval hibernation of Epilachna admirabilis (Coleoptera: Coccinellidae). Low Temp. Sci. (Ser. B) 38: 69-75.

HoshiKaWA K. 1981: Notes on adult hibernation of Epilachna admirabilis, with special reference to comparison with larval hibernation (Coleoptera: Coccinellidae). Low Temp. Sci. (Ser. B) 39: 9-20.

HoshiKawa K. 2000: Seasonal adaptation in a northernmost population of Epilachna admirabilis (Coleoptera: Coccinellidae). Jpn. J. Entomol. 3: 55-63.

Huggans J.L. \& BlickenstafF C.C. 1964: Effect of photoperiod on sexual development in the alfalfa weevil. J. Econ. Entomol. 57: 167-168.

Ikeda-Kikue K. \& Numata H. 2001: Timing of diapause induction in the cabbage bug Eurydema rugosum (Heteroptera: Pentatomidae) on different host plants. Acta. Soc. Zool. Bohem. 65: 197-205.

Ishihara M. \& Hayashi T. 2000: Photoperiodic induction and termination of adult diapause in the willow leaf beetle, Plagiodera versicolora (Coleoptera: Chrysomelidae). Entomol. Sci. 3: 439-441.

ITo K. \& NAKATA T. 2000: Geographical variation of photoperiodic response in the females of a predatory bug, Orius sauteri (Poppius) (Heteroptera: Anthocoridae) from northern Japan. Appl. Entomol. Zool. 35: 101-105.

KatakURA H. 1976: On the life cycle of Epilachna admirabilis (Coleoptera, Coccinellidae) in Sapporo, Northern Japan, with special reference to its hibernation by adult stage. Kontyu, Tokyo 44: 334-336.

Kawano T. 1934: Studies on the life-history of Epilachna admirabilis Crotch. Kontyu 8: 138-153. 
Kida Y., Numata H. \& FujII H. 1997: Summer diapause in females of Minois dryas (Lepidoptera: Satyridae). Environ. Entomol. 26: 201-206.

KIRITANI Y. 1987: Effect of stationary and changing photoperiods on oviposition in Carbula humerigera (Heteroptera: Pentatomidae). Appl. Entomol. Zool. 22: 29-34.

KonO Y. 1986: Photoperiodic control of ovarian development in the 28 spotted lady beetle, Henosepilachna vigintioctopunctata. Appl. Entomol. Zool. 30: 87-92.

Kurosawa Y., Hisamatsu S. \& SasajI H. 1985: Colored Illustrations of the Coleoptera of Japan Vol. 3. Hoikusha, Osaka, $500 \mathrm{pp}$.

MAKI T. \& KurIHARA M. 1965: Effect of temperature on reversibility of ovarian development in the lady beetle, Epilachna vigintioctomaculata Motschulsky. J. Fac. Agric. Iwate Univ. 7: 167-171

MAKI T., KuRIHARA M. \& ANDO Y. 1964: On the reversibility of the ovarian development of the lady beetle, Epilachna vigintioctomaculata Motschulsky, by the photoperiodic effects. J. Fac. Agric. Iwate Univ. 7: 7-17

MASAKI S. 1956: The local variation in the diapause pattern of the cabbage moth, Barathra brassicae Linné, with particular reference to the aestival diapause (Lepidoptera: Noctuidae). Bull. Fac. Agric. Mie Univ. 13: 29-46.

MASAKI S. 1980: Summer diapause. Annu. Rev. Entomol. 25: $1-25$.

Matsumoto Y. 1959: The reduction of pre-oviposition period in the adults of the vegetable weevil, Listroderes costirostris obliquus Klug., by the short-day and low-temperature rearing with some discussion on their aestivation. Nogaku Kenkyu 46: 218-225.

McMullen R.D. 1967: The effects of photoperiod, temperature, and food supply on rate of development and diapause in Coccinella novemnotata. Can. Entomol. 99: 578-586.

NAGASAKA K. 1992: Why does only Athalia japonica enter summer diapause among three sympatoric Athalia sawflies feeding on crucifers? Res. Popul. Ecol. 34: 383-395.

National Astronomical ObSERVATORY (ed.) 1994: Chronological Scientific Tables. Maruzen, Tokyo, 1042 pp.

Nechols J.R. 1988: Photoperiodic resposes of the squash bug (Heteroptera: Coreidae): Diapause induction and maintenance. Environ. Entomol. 17: 427-431.
Nisimura T., Kon M. \& Numata H. 2002: Bimodal life cycle of the burying beetle Nicrophorus quadripunctatus in relation to its summer reproductive diapause. Ecol. Entomol. 27: 220-228.

NoDA T. 1984: Short day photoperiod accelerates the oviposition in the oriental green stink bug, Nezara antennata Scott (Heteroptera: Pentatomidae). Appl. Entomol. Zool. 19: 119-120.

Numata H. \& Hidaka T. 1982: Photoperiodic control of adult diapause in the bean bug, Riptortus clavatus Thunberg (Heteroptera: Coreidae) I. Reversible induction and termination of diapause. Appl. Entomol. Zool. 17: 530-538.

OKuda T. \& Hodek I. 1994: Diapause and photoperiodic response in Coccinella septempunctata brucki Mulsant (Coleoptera: Coccinellidae) in Hokkaido, Japan. Appl. Entomol. Zool. 29: 549-554.

SCHAEFER P.W. 1983: Natural enemies and host plants of species in the Epilachninae (Coleoptera: Coccinellidae) - a world list. Agric. Exp. Stn. Univ. Delaware Bull. 445: 1-42.

TAKeUCHI M. \& TAMURA M. 1994: Life cycle of two populations of Epilachna admirabilis feeding on different host plants. Jpn. J. Appl. Entomol. Zool. 38: 79-84.

Tanaka S.I., Imai C. \& Numata H. 2002: Ecological significance of adult summer diapause after nymphal winter diapause in Poecilocoris lewisi (Distant) (Heteroptera: Scutelleridae). Appl. Entomol. Zool. 37: 469-475.

TAuber M.J. \& TAUber C.A. 1972: Geographic variation in critical photoperiod and in diapause intensity of Chrysopa carnea (Neuroptera). J. Insect Physiol. 18: 25-29.

TAuBER M.J. \& TAuBER C.A. 1976: Insect seasonality: Diapause maintenance, termination, and postdiapause development. Annu. Rev. Entomol. 21: 81-107.

TAYLOR F. \& SCHRADER R. 1984: Transient effects of photoperiod on reproduction in the Mexican bean beetle. Physiol. Entomol. 9: 459-464.

Thiele H.-U. 1969: The control of larval hibernation and of adult aestivation in the carabid beetles Nebria brevicollis F. and Patrobus atrorufus Stroem. Oecologia 2: 347-361.

UCHIDOI T. \& TAKEDA M. 1997: A unidirectional change in daylength: A token for photoperiodic regulation of prepupal diapause in Athalia japonica (Tenthredinidae). Appl. Entomol. Zool. 32: 471-476.

Received February 2, 2004; revised April 13, 2004; accepted October 4, 2004 